\title{
Factor Structure Of Deterrents To Adult Participation In Higher Education
}

\author{
Naveen K. Malhotra, (Email: malhotnk@eckerd.edu), Eckerd College \\ Morris Shapero, (E-mail: shaperma@eckerd.edu), Eckerd College \\ Steve Sizoo, Eckerd College \\ Tom Munro, Eckerd College
}

\begin{abstract}
As institutions of higher learning have seen the aging of American college students, they have been increasingly concerned about helping them overcome what deters their reentry. Adult perception of deterrents is identified in this study. Analysis and the factor structure underlying these deterrents is examined in the Situational, Institutional, and Dispositional category of deterrents. Six factors with no extraneous items were identified: bad experience, institutional reasons, lack of resources, course offerings, cost/benefit ratio and childcare were identified for potential adult students at a small private tuition-driven undergraduate college. This complex set of findings fits with barriers established in the literature. Bad Experience, a dispositional barrier, and the Institutional factor correspond to Cross' (1981) typology. Lack of Resources and Course Offerings are spread among situational, institutional and dispositional factors. Cost/Benefit Ratio is situational and institutional. Childcare is situational. This study contributes to a complex model of deterrents to participation.
\end{abstract}

\section{INTRODUCTION}

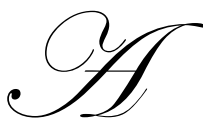

dult education is undergoing rapid growth as a result of demographic, social, economic, and technological changes. Due to demographic changes, the median age in the United States is now over 34 years. With middle age approaching, baby boomers are reaching plateaus in the work place. They expect increased wages, promotions, and higher standard of living. Since the mature American economy is slow in providing these things to them, this has far-reaching social, political, and economic ramifications.

Adult education is primarily a voluntary activity. Often, adults engage in educational activities as a result of needs and expectations of society (Kerka 1986). Because the global economy requires a better-educated worker (Keegan, 1998), and due to the increase in the use of technology in the workplace many adults seek more schooling (Burns 2001). In response, adults have returned to school, a demographic development that has created an adult education revolution.

The adult student enrollment in postsecondary education increased from 2.4 million in 1970 to 6.5 million in 2000 (Aslanian 2001). The number of adult learners aged 35 and over increased more than 250 percent ( Kasworm, Sandermann, and Sissel 2000). Although adult learners are a common sight on many college campuses, a persistent belief among many college faculty and administrators is that the typical college student is under age 22 . A report by United States Department of Education reveals that 73 percent of undergraduate students today are considered to be 'nontraditional' by virtue of their age and financial status (Jamilah 2002). They still have unequal access to educational opportunity. Adults with workplace challenges and family pressures experience a very different set of educational conditions than the traditional age students. The difficulties experienced by nontraditional learners are called barriers to participation. Cross (1981), classified barriers into three categories: situational, institutional and dispositional. Situational barriers arise from one's situation in life. Institutional barriers are practices and procedures that exclude or discourage working adults from participating in educational activities: inconvenient schedules or locations, inflexible school fees, inappropriate course offerings, etc. Dispositional barriers are negative attitudes and perceptions about returning to school that limit student success (Brookfield, 1986; 
Charner, 1980; Cross \& McCarthan, 1984). To satisfy needs of prospective students colleges need to understand obstacles to participation perceived by these learners.

Adult learners' participation in higher education is a complex phenomenon involving varied reasons. Adults are often affected by situational factors such as job, health problems, financial or legal difficulties, personal or family problems, which may not be under their control (Belzer 1998). Likewise, dispositional factors of expectations, self-esteem, level of family support, and prior educational experience can deter participation (Hubble 2000). Institutional red tape, program fees, scheduling, and procedures are institutional factors that can either help or hinder participation (Quigley 1998). Most research on participation describes the deterrence construct among the general population or populations at large public universities. In addition, such research has concentrated on adult learners who were currently enrolled. The purpose of this study is to identify the barriers to participation perceived by potential adult students at a small private tuition-driven undergraduate college. To help college administrators understand better the deterrence construct, the types of educational barriers that are perceived to exist by potential adult students were explored. Further, the underlying structure to the reasons for non-attendance is examined.

\section{RELATED RESEARCH}

Much of the early participation research was descriptive. Scholars tended to concentrate on demographic variables. A synthesis of their summary findings is listed below:

1. Workers and students learn mainly to make career transitions, homemakers and retirees learn to make family transitions and for leisure (Aslanian \& Brickell, 1980).

2. As income rises, adults learn more often for career reasons (Mishler \& Moss, 1986).

3. As occupation level rises, adults learn more often for career reasons (Mishler \& Moss, 1986).

4. Men learn more often than women because of career changes, while women learn more often because of family, leisure or health transitions (Cross 1981).

5. Adults who have attended four-year colleges learn more often for their careers, while adults who have attended high school or junior colleges learn most often for family or leisure activities (Cross 1981).

6. Adults below the typical retirement age of 65 learn mainly because of career transitions, while senior citizens learn mainly because of leisure and family transitions (Cross 1981).

7. Adults who are single, married or divorced learn mostly because of their careers, while widowed persons learn mostly because of their family activities and leisure (Aslanian \& Bickell, 1980).

Explanatory research highlighted factors that motivate participation in nontraditional adult education, with the work of Houle (1961) being especially influential. He concluded that participation in adult learning activities was induced by goal-oriented, activity-oriented or learning-oriented types of motivation. Beder and Valentine (1987) found 10 basic motivations for participation among adult students: self-improvement, family responsibility, diversion, literacy development, community/church involvement, job achievement, launching, economic need, educational advancement, and the urging of others.

As a general theory of motivation, Lewin's (1951) force-field analysis postulates that behavior is a result of competition between driving and restraining forces. Miller (1967) proposed a 'push-pull' theory in which positive driving forces push an adult toward participation in higher education while negative, restraining factors pull the person away. Adult participation depends on the degree of congruence or conflict between the persons' needs and the perceived strength of the social and situational factors in the decision. Catalano (1985) added a third dimension to the non-educational aspects of the person's life into the decision process. Based on Maslow's hierarchy of needs (1943) and Herzberg, Mausner, and Snyderman's (1959) motivators and hygiene factors, Catalano combined the concept of cost/benefit (barrier/goal) with the notion than an adult's decision to enter college will be ranked in terms of the priority of needs in the persons' life. Catalano's model highlights opportunity cost, which includes tuition, books and supplies, income foregone, time spent studying, loss of social activities, and the effort applied to planning and pursuing a degree. 
Although motivational research has been an important focus, it has been only one dimensional in explaining differences between participants and non-participants.

\section{BARRIERS TO LEARNING}

It is important to know why adults do not participate. Barriers to participation generally have been examined through census-type surveys where respondents volunteer reasons for non-participation. Johnstone and Rivera (1965) noted that barriers could be classified as situational, which are external to an individuals' control, and dispositional, based on personal attitude. Carp, Peterson, and Roelfs (1973) analyzed the learning activities of adults already engaged in learning. The barriers in order of importance were: cost, not enough time, not wanting to attend school full-time, home responsibilities, job responsibilities, and the amount of time required to finish the program. Shipp and McKenzie (1981) postulated that the psychographic profiles of non-learners showed that they were oriented less to the future than to the past or present, had shorter time perspectives, emphasized emotional response more than rational, felt little personal freedom, were less willing to take risks, thought more concretely, depended more on family and friends for advice, and were more action-oriented. On the other hand, learners were considered to be more future-oriented, felt more freedom, were more willing to take risks, thought more abstractly, sought more professional and expert advice, had longer time perspectives, and emphasized rational responses. Cross (1981), added 'Institutional barriers' to the mix and classified Carp, Peterson, and Roelfs' barriers as situational, institutional, and dispositional. Scanlan (1984) reviewed the literature on deterrents to participation, concluding that there were six robust categories of deterrents that emerged in most settings and with most populations: individual, family, home-related problems; cost concerns; questionable worth or relevance of educational opportunities; negative perceptions of the value of education; lack of motivation or indifference to learning; and lack of selfconfidence. Manning \& Vickery (2000) compiled six deterring factors: personal disengagement, lack of program quality, work constraints, cost, family constraints and professional disengagement.

Darkenwald and Valentine (1990) concluded that the decision not to participate in organized adult education is typically due to the combined or synergistic effects of multiple deterrents, rather than just one or two in isolation. Martindale and Drake (1989) factor analyzed the Deterrence to Participation Scale (DPS-G) for a specific population of U.S. Air Force enlisted personnel, finding eight barriers: lack of course relevance, lack of confidence, cost, time constraint, lack of convenience, lack of interest, family problems, and lack of encouragement.

Subsequent research (Martindale and Drake, 1989; Beder, 1990; Domberg and Winters, 1993; Malhotra, 1997; Belzer, 1998; Quigley, 1998; and Hubble, 2000) has confirmed the intuitive classification of barriers (Cross, 1981; Johnstone and Riviera, 1965; Carp, Peterson and Roelfs, 1973) and improved the understanding of forces that deter participation. It further suggests that the internal psychological variables of self-concept and attitude towards learning are important decision points. A learner has to overcome the mental resistance of conflict between motivation and deterrents.

\section{METHODOLOGY}

The present study attempts to identify the barriers to participation perceived by potential adult students at a small, private, tuition-driven undergraduate college. The types of deterrents that are perceived to exist by these students are examined, and the underlying reasons for nonattendance are explored.

\section{Data Preparation And Analysis}

An alphabetical list of 1500 students, who attended an informational session about the program and had an individual conference with the admission staff but did not enroll, was obtained from a small, private, tuition-driven undergraduate college. A stratified sample of 500 potential students received the 'Learning Interests and Experiences of Adult Americans' survey by Carp, Peterson, and Roelfs (1973). The psychometric qualities of the instrument were judged to be above acceptable levels. One hundred and fifty five completed surveys were returned. 
To explore the educational barriers perceived to exist by potential learners, the mean and standard deviation was computed for each barrier (Table 1). To further understand the underlying structure to reasons potential nontraditional students fail to attend college, the 24 nonparticipation items were subjected to factor analysis (principal components with varimax and oblique rotation). Factor analysis, a population specific procedure provides an empirical basis for reducing many variables to a few factors by combining variables that are moderately or highly correlated to each other. Each factor must explain a relatively large portion of the variance found in the variables, and each factor must be more or less independent of every other factor. The goal of factor analysis is to identify the not-directly-observable factors based on a set of observable variables.

\section{FINDINGS}

\section{Reasons For Nonparticipation}

Table 1, lists the mean scores for each item. These summary statistics for all indicators address what specific barriers are perceived as most discouraging by nontraditional students. The variables with the highest mean scores, which indicate the greatest average amount of concern were Cost of books and tuition (3.4), Not enough time (3.4), Job responsibilities (3.0), and Amount of time required to complete program (2.9). The lowest average amount of concern were indicated by Hesitate to seem too ambitious (1.3), Friends and Family don't like the idea (1.3), and No transportation (1.2). A majority of item means were low, suggesting that the decision not to participate in structured learning is due to the synergistic effects of the multiple deterrents. These generally support earlier research. Three of the first four items are situational (Cross, 1981), while three of the first six are institutional. These items are distributed across four of the six factors subsequently identified.

Table 1

\section{Descriptive Statistics for Barriers to Participation}

\begin{tabular}{lll} 
Item & Mean & SD \\
\hline Cost of books, and tuition & 3.4 & 1.18 \\
Not enough time & 3.4 & 3.0 \\
Job responsibilities & 2.9 & 1.03 \\
Amount of time required to complete the program & 2.7 & 1.17 \\
Courses not scheduled when I can attend & 2.7 & 1.13 \\
Home responsibilities & 2.5 & 1.26 \\
Not enough energy or stamina & 2.1 & 1.09 \\
Courses I want seem to be unavailable & 2.1 & 1.18 \\
Don't want to go to school full-time & 2.0 & 1.30 \\
No way to get college credit for a degree & 1.9 & 1.05 \\
Strict attendance requirements & 1.9 & 0.95 \\
Don't enjoy studying & 1.8 & 0.99 \\
Tired of going to school and classrooms & 1.7 & 0.95 \\
No information on places or people offering courses I want & 1.7 & 0.96 \\
Low grades in the past, not confident in my ability & 1.6 & 1.07 \\
Have no educational goals or direction & 1.5 & 0.87 \\
No place to study or practice & 1.5 & 0.84 \\
No child care & 1.4 & 1.02 \\
Afraid I'm too old to begin & 1.3 & 0.80 \\
Don't meet requirements to begin the program & 1.3 & 0.68 \\
Too much red tape in getting enrolled & 1.3 & 0.67 \\
Hesitate to seem too ambitious & 1.3 & 0.68 \\
Friends or family don't like the idea & 1.2 & 0.80 \\
No transportation & & 0.59
\end{tabular}




\section{Factors Underlying Nonparticipation}

Although the means and standard deviations of reasons for nonparticipation are useful for the purpose of description, collectively the number of items shows a snapshot too complex to understand easily. As a result of the analysis, six factors were identified: Bad Experience, Institutional Reasons, Lack of Resources, Course Offerings, Cost/Benefit Ratio, and Child Care. Table 2 lists the complexity of the 24 potential reasons for nonparticipation suggesting that factor analysis is a way to clarify the structure underlying the descriptive statistics.

Table 2

Factor Structure for Barriers to Participation

\begin{tabular}{|c|c|c|}
\hline Load & Mean & Item \\
\hline \multicolumn{3}{|c|}{ Factor I Bad Experience (Mean item score $=1.6$ ) } \\
\hline .72 & 1.7 & Low grades, not confident of my ability \\
\hline .70 & 1.9 & Don't enjoy studying \\
\hline .67 & 1.4 & Afraid I'm too old to begin \\
\hline .64 & 1.8 & Tired of going to school and classrooms \\
\hline .60 & 1.3 & Don't meet requirements to begin program \\
\hline \multicolumn{3}{|c|}{ Factor 2 Institutional (Mean item score $=1.4$ ) } \\
\hline .74 & 1.2 & No transportation \\
\hline 60 & 1.3 & Friends or family doesn't like the idea \\
\hline .58 & 1.3 & Too much red tape in getting enrolled \\
\hline .50 & 1.5 & No place to study or practice \\
\hline .48 & 1.3 & Hesitate to seem too ambitious \\
\hline \multicolumn{3}{|c|}{ Factor 3 Lack of Resources (Mean item score $=3.0$ ) } \\
\hline .78 & 3.4 & Not enough time \\
\hline .76 & 3.3 & Job responsibilities \\
\hline .70 & 2.7 & Home responsibilities \\
\hline .53 & 2.5 & Not enough energy or stamina \\
\hline .53 & 2.9 & Amount of time required to complete \\
\hline \multicolumn{3}{|c|}{ Factor 4 Course Offerings (Mean item score $=2.2$ ) } \\
\hline .76 & 2.1 & Courses I want seem to be unavailable \\
\hline .71 & 2.7 & Courses not scheduled when I can attend \\
\hline .52 & 1.7 & No information about places or people offering what I want \\
\hline \multicolumn{3}{|c|}{ Factor 5 Cost/Benefit Ratio (Mean item score $=1.9$ ) } \\
\hline .71 & 1.9 & Strict attendance requirements \\
\hline .64 & 2.0 & No way to get credit for degree \\
\hline .41 & 2.1 & Don't want to go to school full-time \\
\hline .37 & 1.6 & Have no educational goals or direction \\
\hline \multicolumn{3}{|c|}{ Factor 6 Child Care (Mean item score $=2.5$ ) } \\
\hline .72 & 1.5 & No child care \\
\hline .55 & 3.4 & $\begin{array}{l}\text { Cost of books, learning materials, child care, transportation, } \\
\text { and tuition }\end{array}$ \\
\hline
\end{tabular}

The initial factor analysis gave seven factors with eigenvalues greater than one. Following the literature and a scree test, a six-factor solution was chosen. The first factor, Bad Experience, contains items such as Low grades in the past, not confident of my ability, Afraid I am too old to begin, and Don't meet requirements to begin program, along with Don't enjoy studying and Tired of going to school, tired of classrooms. These items are dispositional (Cross, 1981) and relate to Martindale and Drake's (1989) Lack of Confidence and Lack of Interest. The "Don't enjoy studying" item corresponds to Beder's (1990) Dislike for School. 
The Institutional factor corresponds closely to Cross' (1981) Institutional set of factors. No transportation, Too much red tape in getting enrolled, Hesitate to seem too ambitious, and Friends and family don't like the idea are institutional. The fifth element item that loaded on this factor, No place to study or practice is situational. The Friends and Family item corresponds with Martindale and Drake's Family Problems and Lack of Encouragement. The transportation and red tape items correspond with Martindale and Drake's (1989) Lack of Convenience.

Lack of Resources, contains Not enough time, Job responsibilities, Home responsibilities, Not enough energy or stamina, and Amount of time required to complete the program. The responsibility and energy items formed a factor along with the time items (Martindale and Drake, 1989). These are spread across Cross' (1981) situational, institutional and dispositional barriers.

Course Offerings, contains Courses I want don't seem to be available and Courses I want aren't scheduled when I can attend, from which its name is derived, and No information about places or people offering what I want. These are dispersed across Cross' (1981) categories and they correspond with Martindale and Drake's (1989) Lack of Course Relevance and Lack of Convenience.

Cost/Benefit ratio, contains Strict attendance requirements, No way to get credit for a degree, and Don't know what I would like to learn or what it would lead to, all situational, and Don't want to go to school full time, an institutional factor according to Cross (1981). This corresponds with Martindale and Drake's (1989) Cost factor.

Childcare, contains No childcare and Cost, including books, learning materials, childcare, transportation, as well as tuition. The second is a catchall item. These are situational factors. Childcare has not emerged as a separate factor in other studies.

The six factors explain a total of $58 \%$ of the variance, accounting for $26 \%, 8 \%, 6 \%, 5 \%$, and $5 \%$. Table 2 shows that mean item scores are 1.6, 1.4, 3.0, 2.2, 1.9, and 2.5, suggesting that Lack of Resources is perceived as the most important barrier.

In conclusion, the 24 questionnaire items formed six factors with no extraneous items. The factors were consistent with the literature.

\section{DISCUSSION}

The emerging typology resulting from this study adds to what is currently documented about deterrence to adult participation. In particular, it attempts to describe how various forces deter a specific subpopulation from reentering college. Adults choose not to participate in higher education for complex reasons. The reasons are: bad experience, institutional reasons, lack of resources, course offerings, cost/benefit ratio, and childcare. These findings are not surprising; they fit with reasons well established in the literature.

Bad experience, a dispositional barrier, and the institutional factor correspond to Cross' (1981) typology. Lack of resources and course offerings are spread across Cross' situational, institutional and dispositional factors. Cost/Benefit Ratio is situational and institutional according to Cross (1981). Childcare is situational.

Scholars are fleshing out the complicated model of deterrents to participation. A full model could be useful in learning why some participate in higher education and others do not. Such understanding can be combined with existing research into a dynamic model of participation in adult education. This knowledge is also a useful input in marketing educational programs to adults.

The role of the educational institution also needs to be examined. Most academic programs were designed for traditional learners and later used by adult students. The special needs of adults should be paramount in the minds of program administrators as they design non-traditional programs. Individual advising, personal attention, and advisor follow-up and support are imperative for adults. Development theory suggests that education is a lifelong process and not an event. Pursuing higher education as an adult taxes various levels of human resources. 
Many sub-steps are required that demand investment of time, money, planning, and sheer human energy. Arrangements must be made to accommodate the changes in the lifestyle that a return to school inevitably demands (Johnson \& Hartmann 2000).

\section{IMPLICATIONS FOR PRACTICE}

What may be most notable about these results is the persistence and resourcefulness of respondents. Students employ a variety of strategies and resources to manage their lives to include further education, even under conditions of great difficulty. Further exploration of these management strategies could be the subject of future research on adult education programs, and could yield additional information on how institutions of higher learning can facilitate the attainment of a college education by the mature student.

The results of this study can be used by program developers and practitioners to enhance enrollment and retention. Information about perceived institutional barriers can be addressed by colleges and universities. Situational and dispositional barriers, while more difficult to address directly, can sometimes be modified by an adult-friendly institutional environment. Knowing about which barriers are perceived, as the most serious by these students can help create more supportive educational environments. Specific strategies need to be developed to aid adult learners in overcoming the deterrents to educational participation they experience. More specifically, lower course fees, financial aid, delayed payment plans, and credit card options should appeal to adults primarily deterred by cost considerations. For those deterred by dispositional barriers, positive promotional messages, peer-support groups, personalized course requirements, and 'no-credit-yet' grading are useful techniques to employ. Auditing classes may give nontraditional students a sense of their preparedness level prior to enrolling for credit. Classes for newly returned students could be structured as non-competitive, or set up to provide success experiences. 'Fresh Start' programs, in which returning students earlier academic record is expunged, could be attractive to students with difficulties in their past academic career. For those with poor grades in the past, advisors could proactively provide academic review and counseling after each course. Remedial assistance could be then identified early in the students' enrollment and rectified. Additional instruction in basic survival skills, such as time management, basic math, reading skills, public speaking, test taking, and study habits should also be available.

Another area in need of attention for program planners is academic advising for nontraditional students. Adult learners require definitive long-range degree planning to minimize scheduling conflicts, since they accommodate many roles of adult life in addition to their role as a student. Academic advisors to nontraditional students need to be aware of the students' career goals, and be prepared to assist in the selection of appropriate coursework. When problems arise or information is needed, nontraditional learners find it difficult to visit campus offices during normal business hours. Office hours and availability of information should be adapted to accommodate the lifestyles of adult learners.

An ombudsman's office can be established, staffed by personnel familiar with institutional policy and procedures. This office would have the authority to reduce red tape and solve individual student problems. Kara and DeShields (2004) suggest that higher educational institutions utilize a more consumer-oriented philosophy in delivering their programs. Consumer-oriented principles may have a better chance of satisfying the wants and needs of their students more effectively. Institutions should also develop alternate means of organizing outreach adult education faculty who incorporate advising and counseling responsibilities into their position descriptions. Institutional policy could also be made friendlier to nontraditional students. Lana Low (2000) suggests that satisfaction of college students is an important indicator of persistence. Successful institutions focus on the needs of their students, continually improve the quality of the educational experience, and use student satisfaction data to shape their directions. Allocation of institutional resources could be uncoupled from class size, since adult classes tend to be smaller on average. Program offerings could be based on needs assessment, and targeted appropriately. DeShields, Kara, \& Kaynak (2005) postulate that the changing nature of the higher education marketplace encourages college administrators to apply the consumer-oriented principles that are used in profit-making institutions. For adult learners who find that situational barriers hinder their participation, educational institutions should develop policies to support adult learners' decision to return to school. These policies should be aimed at the family unit, in recognition of its importance as a support base for the successful learner. This is particularly true of 
counseling sand childcare services. Another policy might be to organize carpooling for students to resolve transportation issues.

Distance learning technologies might be employed to offer supporting services such as advising or disseminating web-based course registration and financial aid information. Flexible scheduling, such as distance learning, web-based instruction, weekend and evening classes, self-paced learning, workshops, individual tutoring, competency-based learning, workshops, and individual learning projects could be utilized. Tutoring services could be available outside of normal business hours. To promote cohesion and integration among nontraditional learners, program designers could encourage the formation of an adult student organization. A newsletter for this population would provide a tool for disseminating information or coping strategies. In large enough populations, adult student housing might mitigate some of the situational difficulties faced by these students.

Finally, educational policy at the state level could be modified to address proactively the needs of the nontraditional student population. A lack of such policies can indicate an absence of recognition of adult learners, or imply a lack of concern for their difficulties. With the growing ranks of these students, specific state policy needs to be directed at ensuring equal treatment and access to education and financial aid for both full and part time nontraditional students. Currently, financial aid decisions mostly rest with individual institutions.

\section{FUTURE RESEARCH}

Much work needs to be done before the deterrence construct is fully understood. Although the results of this study are consistent with other published research, a useful follow-up might be to study representative national sample of non-participants. The external validity of this study is quite limited. Results cannot be generalized to all nontraditional learners at private, tuition-driven undergraduate colleges, much less the general population of adult learners. It would also be interesting to compare the perception of barriers in this population of students to populations of students served by different kinds of adult programs. This would help validate the categories of barrier classification across populations. Additional research could be undertaken to fully understand the deterrence construct. Replication of this study would be helpful in further establishing its validity. The list of barriers used in this study was representative of the types of barriers found in three categories. However, it is conceivable that social changes may have caused the type of barriers perceived by certain demographic groups, such as women, minorities and foreign-born people to change. To further contribute to the body of literature, longitudinal studies to track participation by specific populations would be equally welcome.

\section{REFERENCES}

1. Aslanian, C. B., \& Brickell, H. M. (1980). Americans in Transition: Life Changes as Reasons for Adult Learning. New York: Future Directions for a Learning Society, College Board.

2. Aslanian, C. (2001). You're Never Too Old: Excerpts From Adult Students Today. Community College Journal, 71, No. 5. 56-58.

3. Beder, H. (1990). Learning, Literacy and Participation. Adult Education Quarterly, 43, 29-38.

4. Beder, H., \& Valentine, T. (1987). Iowa's Adult Basic Education Students: Descriptive Profiles Based on Motivations, Cognitive Ability, and Sociodemographic Status. Des Moines, IA: State of Iowa Department of Education.

5. Belzer, A. (1998). Stopping Out, Not Dropping Out. Focus on Basics. Cambridge, MA: Harvard University. (ERIC Document Reproduction Service No. Ed.457405).

6. Brookfield, S. (1986). Understanding and Facilitating Adult Learning. San Francisco: Jossey-Bass.

7. Burns, L. (2001). When Mothers Become students: Impact on Children and the Family System. Alliance/ACE Conference Proceedings, Austin, Texas.

8. $\quad$ Carp, A., Peterson, R., \& Roelfs, P. (1974). Adult Learning Interests and Experiences. In K. P. Cross, J. R. Valley and Associates, Planning Nontraditional Programs: An Analysis of Issues for Post-Secondary Education (pp. 11 -52). San Francisco: Jossey-Bass.

9. Catalano, J. T. (1985). Keeping College Students in College: A Motivation-Retention Model. College Student Journal, 19, 255-260. 
10. Charner, I. (1980). Patterns of Adult Education in Learning Activities. Washington, D. C.: National Institute for Work and Learning.

11. Cross, P. (1981). Adults as Learners. San Francisco: Jossey-Bass

12. Cross, K. P., \& McCartan, A. (1984). Adult Learning: State Policies and Institutional Practices (ASHEERIC Higher Education Report No. 1). Washington, D. C. Association for Study of Higher Education.

13. Darkenwald, G., \& Valentine, T. (1990). Deterrents to Participation in Adult Education: Profiles of Potential Learners. Adult Education Quarterly, 41,29-42.

14. Domberg, S., \& Winters, S. (1993). Learning Styles and Needs of Adult Learner: The Art \& Science of Entrepreneurship Education, 1, Berea, Ohio.

15. Herzberg, F., Mausner, B., \& Snyderman, B. (1959). The Motivation to Work. New York: John Wiley \& Sons.

16. Houle, C. 0. (1961). The Inquiring Mind. (rev. ed..) Madison, WI: University of Wisconsin Press.

17. Hubble, J. (2000). Intake Procedures as a Factor in Identifying Addressing Barriers of Adult Education Students. Southwest Texas University. (ERIC Document Reproduction Service No. Ed. 443982).

18. Jamilah, E. (2002). Nontraditional Students Dominate Undergraduate Enrollments. The Chronicle of Higher Education. 48 (40), 34.

19. Johnson, R. \& Hartmann, R. (1999). Positioning Adult Learners for Success: A Descriptive Study of Lost Connections. Alliance/ACE Conference Proceedings, Saratoga Sprngs, New York.

20. Johnstone, J.W., \& Riviera, R.J. (1965). Volunteers for Learning. Chicago: Aldine. Keegan, D. (1998) Foundations of Distance Education. London. Routledge.

21. Kara, A. \& DeShields, O. (2004). Business Student Satisfaction, Intentions and Retention in Higher Education: An Empirical Investigation. Marketing Educators Quarterly, 3 (1).

22. Kasworm, C., Sandermann, L., \& Sissel, P. (2000). Adult Learners in Higher Education. Handbook of Adult and Countinuing Education. Editors: A. Wilson, \& E. Hayes. San Francisco: Jossey-Bass.

23. Kerka, S. (1986). Deterrents to Participation in Adult Education. Columbus, OH: Ohio State University. (Eric Document Reproduction Service No. Ed. 275889). Johnstone, J. W., \& Rivera, R. J. (1965). Volunteers for Learning. Chicago: Aldine.

24. Lewin, K. (1951). Field Theory in Social Science. New York: Harper.

25. Low, L. (2000). Are College Students Satisfied? A National Analysis of Changing Expectations. New Agenda Series, 2: (1). Indianapolis, IN. USA Group Foundation.

26. Malhotra, N. (1997). Perceived Situational, Institutional, and Dispositional Participation Barriers to Undergraduate Education for Nontraditional Adult Learners at a Small, Tuition-Driven Private College. (Doctoral Dissertation, University of South Florida, 1997). Dissertation Abstracts, 37,14A.

27. Manning, C. \& Vickery, C. (2000). Disengagement and Work Constraints Are Deterrents to Participation in Continuing Professional Education Among Registered Dieticians. Journal of the American Dietetic Association. Chicago.

28. Martindale, C. J., \& Drake, J. B. (1989). Factor Structure Deterrents to Participation in Off-Duty Adult Education Programs. Adult Education Quarterly, 63-75.

29. Maslow, A. (1943). A Theory of Human Motivation. Psychology Review, 50, 370-396

30. Miller, H. (1967). Participation of Adults in Education: A Force-Field Analysis. Boston, MA: Boston University Center for the Study of Liberal Education for Adults.

31. Mishler, S., \& Moss, F. K. (1986). From Traditional to Nontraditional Scheduling: Planning for Saturday Students. Innovative Higher Education, 11 (1), 44-55.

32. National Center for Education Statistics. (1999). Participation in Adult Education. Washington, D. C.: U.S. Dept. of Health, Education \& Welfare.

33. Powell, S. (1989). Perceptions of Barriers to Undergraduate Education by Nontraditional Students at Selected Non-Public Liberal Arts Institutions. (Doctoral Dissertation, Memphis State University, 1990). Dissertation Abstracts, 50, 12A.

34. Quigley, B. (1998). The First Three Weeks: A Critical Time for Motivation. Focus on Basics. Cambridge, Ma: Harvard University. (ERIC Document Reproduction Service No. Ed. 431868).

35. Scanlan, C. (1984). Identifying Deterrents to Participation in Continuing Education. Adult Education Quarterly, 34, 155-166. 
36. Shipp, T., \& McKenzie, L. R. (1981). Adult Learners and Non-Learners: Demographic Characteristics as an Indicator of Psychographic Characteristics. Adult Education, 31 (4), 187-198.

\section{NOTES}

